\title{
Identity Lost and Found: Architecture and Identity Formation in Kuwait and the Gulf
}

\author{
Roberto Fabbri
}

\section{INTRODUCTION}

Among the Gulf countries, Kuwait was one of the first to undergo rapid urban development. From the early 1960s to the late 1980s Kuwait catalyzed the attention of major international designers working with local firms and authorities and leaving on the ground important examples of late modern architecture. As Gulf countries gained independence from the British protectorate, the necessity of a new landscape to represent the fresh founded state grew high. At the same time, architects saw here the possibility to expand their professional horizons, to experiment and to shape an entire city almost from scratch. The extraordinary presence of valuable designers operating almost simultaneously in the same cities is a rare event in architectural recent history. However, such fast transformations raised concerns of superimposing a different identity over local traditions, despite Kuwaitis being at the time mostly in favor of complete demolition of the

\footnotetext{
R. Fabbri $(\bowtie)$

University of Monterrey, Monterrey, Mexico

e-mail: roberto.fabbri@udem.edu
}

(C) The Author(s) 2020

115

M. Karolak, N. Allam (eds.), Gulf Cooperation Council Culture

and Identities in the New Millennium, Contemporary Gulf

Studies, https://doi.org/10.1007/978-981-15-1529-3_7 
old town. Currently, the lack of information and the misconception about the architecture produced in that season arise, while the population shows disaffection and a low sense of belonging to these spaces. Meanwhile, very few measures have been adopted in the past years to promote the conservation or the reuse of this heritage that, after all, represents the modernization era. Recently, some local institutions and parts of the civil society took action against the wiping of shared memories. These bottom-up initiatives started with a series of awareness campaigns and studies that call for preservation. This new attention is significant since all the post-oil Gulf cities were built in large part on a similar pattern, implying local visions, western know-how and Asian workforce. This process set the physical environment and embodied the visual identity of the new nations. Consequently, the architecture produced by this complex geography should be considered a legitimate part of a search for a khaleeji identity.

In this framework, the present chapter investigates the modern architectural Gulf heritage as a possible element of collective identification. Focusing on Kuwait, it proposes to read the so-called 'imported' buildings as an intersection of indigenous narratives and historical patterns with cosmopolitan breath and technical knowledge. The aim is to question if modern architecture could be perceived as a plausible agent of identity-making in Gulf cities.

The present study draws on original data collected in Kuwait and the Gulf between 2010 and 2016. It also builds on the debates, the exhibitions organized in the same period and on two books published in the framework of research grant from the Kuwait Foundation for the Advancement of Sciences, which systematically identified and monitored the architecture in the country. Focusing on the notion of identity, this text builds on the previous results and moves forward in interpreting the significance of selected specimens.

\section{IDENTITy, IdENTITy Lost and Tradition In Transition}

There is a strong connection between traditions, identity and the physical environment produced or inhabited by a society. The process of identity and social formation, and the cultural practices of individuals, as well as groups, are deeply influenced by their habitat (Gieseking and Mangold 2014 , p.73). The notion of place-identity, initially introduced by Proshansky, Fabian and Kaminoff, consists of knowledge and feelings generated by one's everyday experiences of the built environment. The latter 
functions as a generator of memories and sense of belonging, creating meanings and mitigating changes (1983, p.57). At the same time, places, buildings and urban spaces are able to engender specific messages to build or foster national identities.

For the architectural critic Deyan Sudjic, architecture built in small countries acts as a crucial factor to project their presence on a global scale, as well as to represent and express a sense of self. In his text about architecture and power, Sudjic questions how much this process is self-conscious, artificial or an "authentic reflection of individual traits, of climate, materials and customs?" $(2005$, p.250). In other words, the relation between the societal or state narrative and architecture can simultaneously be a process of researching, defining, expressing and manufacturing identity.

At the beginning of the twentieth century, Kuwait was a port town of 40 thousand inhabitants sustained by trades, semi-nomadic livestock rearing and fishing. It has been a British protectorate since 1899. The local culture was a blend of distinct and coexisting maritime and desert traditions, amalgamated by the solid Islamic faith practiced by the majority of the population: "The physical configuration and appearance of Kuwait were, above all, the product of its ecology, local Arab architectural tradition and style and the spatial requirement of its maritime economy" (Broeze 1997, p.170).

The urbanscape of Kuwait inevitably mirrored the identity of the place. The aerial view of the 1940s reveals a town as an intricate labyrinth of narrow alleys and mud-brick houses seamlessly extending from the port docks to the defensive wall. It was a typical Arab medina of the Gulf that for morphology, uniformity, proportions, colors, materials and typology reflected the residents' lifestyle. As a matter of fact, the prevalent architectural type was the courtyard house, protected from the outside and introvert, which precisely translated social and domestic dynamics into space.

During these years, Kuwait experienced a more traditional life, even though it was not isolated from the outer world. The port and the mercantile activities were opportunities of exchange with other cultures, and the British political agency in town, as well as the American missionary church, contributed to expand the geographical horizon of the country. Moreover, during the 1920s and the 1930s, the country's governmental apparatus and educational system underwent a mild but significant modernization. In the same period, progressive ideas and culture stemming from the emerging modern Arab literature, prevalently Lebanese and Egyptian, informed Kuwait's elite and the local cultural circles with anticolonial ideologies (Al-Ragam 2017, p.48). 
The situation changed radically with the oil-struck in 1938 and in the years after WWII. Sudden affluence and the urgent need for new infrastructures led to an unprecedented urban development, which continued, albeit at a different pace, for the following 40 years. The crucial decade between the mid-1940s and the mid-1950s generated Kuwait's urban original sin: the demolition of the old town in favor of new dwelling units to be built outside the city limits. Two formal actions, taken by Sheikh Abdullah al-Salem al-Sabah, Amir of Kuwait, transformed drastically and irreversibly the built environment of the country and the people's relation with the sense of place. The first action was the adoption of Kuwait First Masterplan, drafted in 1951 by the British firm Minoprio, Spencely and MacFarlane. This plan relocated all residential spaces in peripheral and repetitive neighborhoods, overlapped a geometric road network to connect the center with the new satellites, and finally demolished the traditional urban fabric to make space for a new commercial and administrative district. Like in many other urban transformations where massive demolitions were proposed, the plan was motivated and justified by the hygienization of the old quarters, by the practical needs of a modern transportation network, and by the urge of building a capital city that would represent the modern aspirations of an emerging country. Interestingly, in the age of liberation and anti-colonial spirit, Kuwait like many others former colonies resorted to an age-old urban strategy, regrouping the population by class, wealth, religion and ethnicity in disconnected residential districts ( $\mathrm{Al}$ Sayyad 2008, p.257). The second action is a consequence of the first. In the same years, the government promulgated the Land Acquisition Policy to acquire private land inside and outside of the municipal boundaries to implement the Master plan. Under the legal rationale of the public interest, the plots were bought and sold at a highly inflated price, generating market speculations and bitter controversies that affect the land-use potential of the city to these days (Al-Mosully 1992, p.43).

Demolition started immediately after that, proceeding relentlessly with phases defined by the new infrastructure agenda. The aerial pictures of the early 1950s show the new concrete box-type buildings alongside Fahad al-Salem Street emerging from a carpet of semi-demolished mud-brick houses, which now appear physically isolated and visually incoherent with the new context. "What was organic became mechanical," lamented George Shiber, who directly witnessed the destruction's outcomes in his capacity as head of the Planning Board (1964, p.53). The local population, in general, welcomed the flattening of the old town, and very few 
voices spoke in favor of preservation. When Shiber came to office in 1961, he could only document and portray a process already in action: "conventional urban growth patterns were shattered [...]. Old Kuwait exploded and, as it did, it spilled over beyond the once-awesome desert landscape" (p.55). The dismantlement of the old town spared very few buildings: the mosques, the souks, some schools, a few governmental headquarters, the sheikhs' palaces, the diplomatic residences, the Amiri and the American Missionary hospitals, and a meager number of courtyard houses.

Among the few documented voices that stood against the demolition were Violet Dickson and Zahra Freeth, wife and daughter of Harold Dickson, the British Political Agent in Kuwait. They both recall in their publications how the local population seemed indifferent to the systematic removal of that traditional environment which fascinated the two women so much (Freeth 1956, p.83; Jonathan 1981). The Dickson house, once their residence, is currently one of the few pre-oil buildings that survived the demolition and still stand in front of the Gulf. The majority of the local population conveniently accepted to relocate to modern houses in new checkerboard neighborhoods. According to contemporary chronicle, traditional architecture was no longer perceived as suitable, neither acceptable, for modern Kuwaitis (Al-Ba'tha 1949, p.80).

Ironically, the obliteration of the traditional environment did not displace the generation that witnessed it, but deeply affected one or two generations later, while in search of national roots and social identity. As we will see later in this text, the lack of a smooth transition in the architectural transformation of the traditional environment blurred the perception of place-identity, diluted the sense of belonging, and ultimately twisted the collective notion of heritage.

\section{Adopting Modernity. Adapting Modernity}

According to art critic Harold Rosenberg, the condition of modernity is a "tradition of overthrowing traditions" (1959, p.81). His book Tradition of the New was published in 1959 when Kuwaiti modernization was in full swing. Modernity in the sheikhdom was embraced first as a concept by rejecting, or at least profoundly reconsidering, pre-oil traditional life. In many occasions, traditional habits or spaces became synonyms or reminders of the difficulties, the scarcity and the underdevelopment of the past. Only a few core aspects of the traditional customs, namely those concerning family structure, tribal relationships and religion, were less affected or 
rather remained untouched. Modernity was enthusiastically adopted as the new trend, meanwhile, international magazines like LIFE or National Geographic portrayed to the world the extravagant and exotic life in a dreamland, where everything was apparently possible because it could be bought and imported (Frazer 1965; De Carvalho 1965).

In 1964 Herbert Marcuse published One Dimensional Man, depicting a world where people recognize themselves in their commodities, "finding identity (their souls) in their automobiles, hi-fi sets, split-levels homes, kitchen equipment" (p.9). In his analysis, only the outcasts in the West and the Third World were supposedly yet untouched by this process, and therefore able to escape from modernity's kiss of death. Regrettably, the so-called Third World demonstrated not to be immune from this process, and Marcuse's projection ended up to adequately describe the rush to acquire modernity through technology and material goods, which occurred in Kuwait during the 1960s. Almost every family was assigned a plot for a brand-new villa in a residential neighborhood. Nonetheless, modernity was not assimilated seamlessly or equally by every social group. For example, when social housing programs were launched for lowincome families, bitter remarks rose about their difficulties to adapt to new forms of dwelling, to the point that apparently bathtubs were confused for goats feeding troughs, and therefore never used for the real purpose or dismantled (Al-Taher 1995, p.137).

In these years, Kuwaiti houses grew bigger in size and developed extravagant shapes: "Architecture became an exercise in acrobatics and not an endeavor in creation, economics and organicism [...]. It has become rare to find lines anchored to the earth. Instead, they all seem pivoted to point restively to outer space" (Shiber 1964, p.306). Houses embodied naively the country's vision of the future, and often people mistook modernity for an abundance of appliances and house goods. From a morphological point of view, the basic urban component, the house, was not given the time to evolve into a new type based on the contemporary lifestyle and social necessities. The courtyard house, a traditional introverted residential typology where the rooms' sequence reflected a precise hue in the level of privacy, was simply replaced by eclectic concrete shapes with more loose and arbitrary spatial relation. This process was also accelerated by the building codes, based on Western norms, requiring setbacks, which made the courtyard redundant (Al Sayyad 2008, p.258).

In this framework, urgency and the resulting construction speed played an essential, problematic role, and it was reflected in the memoirs of for- 
eign visitors at that time. Donald Barron, a British urban planner, invited by UNESCO, reported: "the paramount problem has been to build quickly" (1967, p.10). R. L. Banks, an American engineer who visited Kuwait in 1955, had the same impression. He published his preoccupation about Western technicians wishing to "introduce the tastes and the standards of Britain and the U.S.A." while they would "have to be slowed down by the warnings of economists and sociologists concerned about the ability of the country to pay for all these things or to adjust itself quickly to all the changes they would bring" $(1955, \mathrm{p} .48)$. Banks concluded that usually the limitation in financial resources slows down the pace of transformations and allows one country to evolve social changes. Because of Kuwait's wealth, the works were restless. Banks reported an "uneven advance" that presented a striking contrast between the "most modern and the most primitive," and representing in his opinion "the most interesting points of contact between East and West" (1955, p.50).

Arif Dirlik affirms that it is not possible to understand modernity without reference to Eurocentrism (2000, p.25). Following this statement, and due to the sustained Eurocentric influence on architectural literature, it will be worth here to propose a brief parallel on how architectural modernity was developed in Europe. Early twentieth-century architecture, often generically referred to as the modern movement, did not reject the past a priori. It instead discarded the Beaux-Art, the historicism, the mimics, the nostalgic sentiments and the non-rational (mis)use of space as well as the unnecessary ( $a b)$ use of decoration. For many champions of the new architecture, modernity was also built through a dialectic relation with the past and the acceptance of the role of history. Modernist architects had to come to terms, in one way or another, with the pre-existing city and calibrate their insert. On the contrary and due to the common practice of demolition, there were very little opportunities in the Gulf to juxtapose the new structures to the pre-existing fabric, so to trigger a dialectic relation. In other words, the old was erased to make space for the new, implying the complete erasure of the past, starting from the pre-oilbuilt environment: the so-called 'tabula rasa' approach. Inevitably, the obliteration of a physical context had profound repercussions on the cultural identity of the place.

One of the major criticisms addressed to the transformations that occurred in the Gulf countries in those decades lies in the difference between 'westernization' and 'modernization'. The cultural and economic penetration of the West offered the possibility to introduce democratic 
reforms and social changes (Watenpaugh 2014, p.4). In Kuwait, however, this was only partially achieved. One can argue that in the aftermath of the independence, the government adopted a new constitution and introduced a parliamentary system - a unique case in the Gulf-among other administrative reforms and social plans. However, it also true that civil and political rights in the country were implemented differently for the citizens and based on social status, ethnicity, religion and gender. Modernity was adopted as an ideal, sometimes as an aesthetic or a device, and then adapted in conformity with traditions, religion and customs. As Noura $\mathrm{Al}$ Sayeh explains, very similar dynamics occurred in Bahrain: "The negotiation between modernity and local tradition was never fully resolved; [...] it was mostly assimilated as a stylistic movement rather than as a political project; never completely absorbed and only partially consumed" (2014, p.8). Similarly, in the last analysis, it seems still pertinent what Bernard Lewis wrote about the earlier transformation process in Turkey, where technological development happened without concurrent belief in emancipation, secularism or rational epistemology: in other words, modernization without commitments to modernity (Lewis 1968, 1992).

\section{Architectural Transplants or Global Mobility? The Diplomatic Role of the Architect}

Modernity in architectural terms is still an open subject. Dismissing any interpretation related to the notion of style, being too reductive, it is still problematic to attempt a convincing categorization of the architecture produced in the central decades of the twentieth century, in particular when new horizons arose out of the usual strongholds, like Europe, North and Latin America. In fact, these new geographies generated a coeval and different type of architectural modernity which can be read as variations on the theme, locally adapted, less orthodox, more experimental and sometimes not entirely resolved. As per Watenpaugh's linguistic metaphor, modernity in post-colonial contexts is a language that maintained transnational intelligibility - to preserve legitimacy - but it was often conjugated in local dialects. At times these dialects lost coherence and lexical uniformity, contradicting the paradigms of the root idiom $(2014$, p. 14).

Modernization in Kuwait resulted in a sort of architectural Esperanto. If so, what type of dialect does Gulf architecture speak? And who were the practitioners that generated this new or different lexicon? What was their understanding and interpretation of place and context? 
Alison and Peter Smithson, who were called to Kuwait in 1968 to develop urban form studies for the old city, preached for projects that could help define a national identity. They called for buildings that, in their words, could carry that "quality" to differentiate Kuwait from other Arab cities, such as Cairo or Beirut. They envisioned buildings within the frame of the Arab urban tradition and adapted to contemporaneity, without variations taken from models in America, in Europe or the Europeanized North Africa (Viadotto 1997, p. 138). The urban form studies for the old city in the late 1960s catalyzed the attention of major international designers. The extraordinary presence of architects, such as Alfred Roth, Balkrishna Doshi, Pier Luigi Nervi, Basil Spence, Reima Pietilä, Kenzo Tange, TAC, SOM, BBPR, George Candilis, Arthur Erickson, I.M. Pei and Jørn Utzon, among many others, operating almost simultaneously in a single city, was indeed a contribution to the desired new image of Kuwait. International commissions were paired by renowned Arab designers also involved in the city's transformation, including Sayyed Karim, Mahmoud Riad, Dar al-Handasah, Hassan Fathy, Mohammed Makiya and Rifat Chadirji, to name a few. Moreover, a new generation of young local architects emerged working side by side with these major firms and this proximity consequently impacted the work they later accomplished independently.

Nonetheless, these rapid changes did shatter social patterns and so fostered the claim of an ignored local tradition. Such critique is still widely diffused, even if Kuwait always was and still is a crossroad between West and East. Its strategic position is deeply reflected in the multicultural society that has developed over the last 60 years, and this complex geography can also be drawn through the professional network of the many actors involved in the city's transformation (Fabbri et al. 2016, pp. 14-15).

In a recent conference and publication on the present and the future of the Arab city, American architectural historian Gwendolyn Wright reflects on the role of migrating architects, and her topic seems poignant in reading here the relationship between identity and architecture. Wright describes Western architects' approach while working in other environments and the potential danger of failing to identify important aspects of local context. During the colonial time, local opinions and needs were not kept in consideration, and in many cases, decisions were enforced on people and layered over the existing urban fabric. Aside from this foreign practice insertion, a plethora of local designers educated abroad completed the scheme by imitating Western patterns. Wright concludes bringing, as an example, the design guidelines issued for internal purposes by the 
American corporate firm SOM, in the 1970s. The document is meant to suggest typologies equally adaptable to the entire Islamic world: indiscriminately from North Africa to India (2016, p.74).

On the one hand, many post-colonial cities in transformation suffered irreparable damage from these planning practices and by the excess of faith in modern design thinking. On the other hand, the present text wants to build upon this prompt within the Kuwaiti context and reflect on the broader implications of the role of the architects and the variables of this architectural transplant. In respect to local identity, how was architecture practiced in the absence of historical heritage, major local references, substantial morphological elements, or evident urban footprint, and occasionally in the absence of adequate planning tools or their correct implementation?

In cities like Beirut, Baghdad or Cairo modern architects had to negotiate spaces and create meanings in relation to an existing urban fabric and a codified architectural tradition, while in Kuwait, as argued above, the traditional city was demolished leaving the designer with very few hints to situate the project. Second, the built environment cannot be considered a direct emanation of the designer alone. The role of local patrons should be considered equally important in defining goals and ambitions during the decision-making process. Third, several designers active in the Gulf had a constant relationship with the region or lived here, developing a deeper understanding of the context through time. This inevitably made their design more aware of the residents' practical and cultural necessities (Wright 2016, p.74). Fourth, significant transformations in Kuwait and the Gulf occurred when the leading principles of the so-called modern movement were under re-consideration. The 1959 CIAM meeting in Otterlo, the Netherlands, emphasized a fracture between the diffused functionalist approach to urban design and an emerging group of younger architects, initially called Team $\mathrm{X}$, that steered their practice toward Structuralism, to generate a methodology that involved more analyses borrowed from sociology, psychology and anthropology. This new direction was meant to distance itself from the formalism and the mechanical functionalism of (some) late modern architecture, and to bring back the people at the center of the design process, with their social relationships, environment, culture and identity. Within this vision, principles like cultural relativism found a more effective role in informing and orienting the design process.

In this framework, the Gulf once again demonstrates to be an interesting case study to understand the evolution of the idea of modernity, since many architects gravitating around Team X had the opportunity to work 
in the area. Alison and Peter Smithson's Mat-Building for Kuwait City; the BBPR's plan for the rehabilitation of the old Souk Mubarakiya, the Candilis' housing complex in Sharq, the Kenzo Tange's airport are all examples of mediating global practice with local circumstances. Unfortunately, several of these examples were not implemented, also because patrons expected signature buildings from renowned international architects, more than a reflexive critique on history, tradition and modernity. Let us consider, for example, Pietilä's use of critical regionalism in the conception of the Ministry of Foreign Affairs (MoFA). The project was an attempt not to mimic native vernacular architecture but to discreetly interweave local narratives and visual patterns within other global cultural themes in order to create a pluralistic aesthetics (Botz-Bornstein 2017, p.76). At the time of the project, the 1980s, foreigners represented $70 \%$ of the resident population in the country therefore MoFA meant to signify the institutions of the cosmopolitan nation. Unfortunately, the attempt at cultural hybridization and social integration did not succeed in representing the national identity in the eyes of the clients, and the building has been deeply altered to the point that the initial concept is barely traceable.

In addition to this, and on the other side of the spectrum, SOM's corporate system, which reduced the complexity of the context to an operative manual, offering standardized solutions, proved to be more successful, at least as a business model. Given the vast number of projects built in the region, the pragmatism, the efficiency and the turnkey offer of the American firm reassured the clients more than Team X's conjectural speculations.

In the Gulf, architects were often given the task to recalibrate the relations between a deliberately forgotten tradition and an undetermined way to modernity, and somehow to recalculate the dynamics between Eastern and Western cultures. Some of them relied on technology and environmental necessities, others on metaphors to represent the national or the client's meanings, other again engaging with concepts like 'authenticity' and 'cultural specificity'. As Amale Andraos puts it, this condition of encounter gave the architect an unexpected diplomatic role to waive past and future into a "mash-up of signifiers for both" (2016, p.9).

\section{Cultural Displacement and a Missing Heritage}

The erasure of the old town did not affect the boom generation of the 1960s; however, 30 years later the lack of physical representation of local roots became a recurrent discourse in the country and intensified particularly 
after the Iraqi Invasion with the urge to reaffirm a well-defined, independent identity.

In 1992, the Kuwaiti filmmaker Habeeb Hussain released a documentary entitled Kuwait Architecture: a Lost Identity. The first part, permeated with nostalgia, is a long sequence shot in the few courtyard houses that still stood, albeit mostly abandoned. Traditional elements of vernacular architecture, like housh (courtyard), liwan (colonnade/passage), teakwood doors and the pointed arches are visually counterposed to concrete components from contemporary successors: balconies, curtain walls, brisessoleil, boxes, pediments and eclectic apertures. Apart from the evocative shots, the importance of this document lies in the numerous interviews with Kuwaiti architects, engineers and public servants employed at the Baladiya (Municipality). The documentary portrays a univocal regret. Every interviewee feels deprived of the past, and the present built environment is generally perceived as an alien intrusion. The majority of interviewees rejects and dismisses modern architecture as non-representative of the local character and people's aspirations, as well as an inadequate response to the harsh climate. Their criticism seems directed more against the generic unauthored private villas, built in every form and shape, sometimes combining several styles in a unique pastiche. As a reaction, these Kuwaiti professionals seem to favor a series of revivalist buildings locally designed, which predictably adapt generic Islamic patterns to the geometrical elements of the façades, solid masses, earthy color palette and lavish interiors. In the commentaries, this combination appeals as a plausible solution and a practical direction to rebalance the lost identity (Hussain 1992).

A decade later, Yasser Mahgoub, at that time visiting professor at Kuwait University, conducted a series of interviews addressing analogous questions to other local professionals and scholars with similar results $(2007$, p.171). The findings reveal that the ample majority again did not see any identity expressed in the modern city. They invoked the promulgation of specific regulations reinforcing Islamic/Arab/desertic characteristics and implementing the use of traditional elements like housh, liwan and diwaniya. The survey reveals a newsworthy, thus univocal, narrative. The limit of the research, however, seems to lie in the selected group of respondents, as they are all professionals who graduated in the 1980s and early 1990s. The survey, therefore, does not engage with the new generation that, as we will see later, is currently very active in the city debates and sees opportunities in modern buildings more than their predecessors. 


\section{IDENTITY RELOADED}

In recent years Kuwait experienced once again an intense construction boom. As a consequence of the 2003 US-Iraq war and the downfall of Saddam Hussein's regime, the country has been perceived as a more stable ground for investments. On top of this, Kuwait's crude oil tripled its value in a decade and, despite a contraction in the last years, the revenues generated a substantial surplus that 'naturally' endowed the speculative real estate market. High rises and crystal towers began to appear in a previously flatter skyline, and even though the city center would have needed more consolidation than intrusions, the construction of skyscrapers mostly happened there (Fabbri, Autumn 2016). In order to make space for these structures, the city center experienced a new demolition wave. Ironically enough, the post-oil concrete city, once accused of being the principal usurper of the traditional town, is now under attack of the bulldozers, and many valuable expressions of the 1960s and 1970s architecture have already been wiped. The latter is mainly due to the fact these buildings sit on valuable plot of land and are not yet perceived as heritage, even if personal and social memories are deeply related to this particular urban environment. Also, this is due to the lack of a legal framework that could guide the transformation and ultimately come to terms with the physical past (Albloushi 2017). The 1960 Antiquity Law and the 1988 Kuwait Heritage Building Registry were never implemented, and in the past 50 years, none of the three master plans has included a preservation chart. Only the 2005 Masterplan Review mentions under "environmental provisions" that historical buildings and archaeological sites shall be mapped and added to the National Register to prevent alterations or demolitions, in a joint effort of the Municipality and the National Council for Culture, Arts and Letters (KEG and Buchanan 2005).

Nevertheless, in the last five years, several modernist buildings were torn down and replaced or altered. Among others, Dar al-Handasah's Kuwait Airways Tower (1969-72) and the Chamber of Commerce (1964-66), and Antony Irvine's Gulf Bank (1961-63) were totally or partially demolished, while the National Bank (1961-63) was cladded with aluminum panels and, as mentioned before, Pietilä's Ministry of Foreign Affairs (1973-83) was heavily altered. The Urban Development Plan 2015-2020 and the 2035 Vision for the country (New Kuwait 2015) promote the construction of satellite cities on remote desert land in response to the chronic lack of residential plots instead of consolidating the city center. 
Similarly, the New Urban Agenda presented in 2016 at the UN Habitat Conference in Quito does not include the notion of heritage as an asset for the city plans (UNHABITAT 2016). In late 2016, the design of the new Masterplan IV-2040 was assigned to Perkins \& Will and Dar al-Handasah with the mandate of aligning the urban form with the Vision 2035. Namely, to transform Kuwait into an international business hub (Fourth Structural Plan Turns Kuwait into Commercial, Financial Hub: PM 2016).

In a context like Kuwait, where the current urban development is happening again fast and under the high pressure imposed by speculative forces, regulations and urban plans proved that they could do very little in terms of preservation. In the last years, awareness campaigns and specific cultural agendas are demonstrating to be a more effective solution to reinterpret the local identity. Cultural institutions and civil society's actions are currently engaging in the quest for an autochthonous cultural DNA suggesting that, due to the cosmopolitan past of the country, any possible definition of a national identity should be written considering the plurality of voices and contributions hinged on collective memories. An initial hint to measure how young people value the problem of cultural displacements in relation to the built environment is given by the many university theses produced in the last ten years around the theme of national identity and architecture in Kuwait. The same generation was also recently involved in sporting Kuwait's architectural 'drama' in the last three editions of the Biennale di Venezia. Public talks, academic seminars and papers, exhibitions, magazines and social media have been the occasions to debate themes such as the accessibility of the city, the perception of a missing public space, the re-demolition of the city center, the current speculative urban development mode and the struggle to establish the notion of heritage.

In 2014, the 1964 Kuwait Chamber of Commerce building was demolished, triggering an unexpected public protest by local and international activists, architects and artists. While these actions are relatively common in other parts of the world, this action was among the first in the region in defense of the modern heritage (Garcia 2014). Two years later, the first systematic study on modern Kuwait in architecture was published, featuring archival research on more than 150 buildings erected between 1949 and 1989, interviews with designers as well as scholars' retrospective analyses (Fabbri et al. 2016; Camacho et al. 2017).

The collective reflections on these themes boosted the emerging practice of place-making: a group action that capitalizes on the community's assets and stimulates the accessibility of public spaces with the double 
outcome of fostering the sense of place and at the same time preserving the built environment (Lanzl et al. 2017). The South Mubarakiya (SOMU) and the Food Strip along the Gulf Road are valid examples of small commercial enterprises introduced in the 1960s city fabric with the logic of 'minimum intervention' on the existing structures. The aim is to introduce non-corporate commercial activities and restaurants not in competition with the pre-existing traditional market. The operation is an uncoordinated and punctual insert of new enterprises privately funded by young investors. The Shakshooka Market, an itinerant pop-up market organized weekly in public spaces, squares and parking lots, also reveals the urge to re-engage with parts of the city that are normally precluded to Kuwaitis' social life. A similar initiative that is interesting for this chapter's argument is the invitation of the Dubai-based French-Tunisian artist El Seed. As a famous muralist and contemporary calligrapher, Seed initially painted medium scale calligraphy on the rooftop of an abandoned building in Kuwait City. Later he was offered the assignment of creating an extensive piece on the lateral elevation of the Thunayan al-Ghanim building, the first multi-story concrete building of Kuwait designed and built by the Egyptian modernist Sayyed Kareem. Calligraphy, probably the most unifying form of art of the Arab world, is applied here with a contemporary style and at the urban scale as a community-engagement operation. Twenty-five people collaborated with the artist over five days to "inculcate a sense of ownership within the larger community and stretches beyond the superficial goal of creating a beautiful landmark" (Nuqat, March 1, 2014).

All these actions are the initiative of an elite minority. Nevertheless, they demonstrate the need to re-engage with the 1960s concrete city, not as a nostalgic scene of a lost past, but as a place of opportunity to express Kuwait's contemporary identity. They blend logics of re-appropriation of underused spaces with the need to transform them into places with character and a sense of authenticity.

\section{Conclusions: Architecture as Common Denominator?}

In the twentieth century, the social and urban development of the Middle East confronted and redefined the notions of tradition, modernity and identity. In particular, the Gulf countries proved to be fast in dismissing the past and in embracing modernity, engaging in a rapid adaptation to changing lifestyle and customs. Later, they also proved to struggle to 
define a convincing national or social identity, and to discover value in their recent past. Gulf cities, initially very traditional and small, experienced a transformation that denatured the spatial relationship between the urban elements and social patterns. The traditional residential typologythe courtyard houses - a key element of the urban morphology, was not given the time to evolve and adapt to the new domestic need.

Moreover, often in the Gulf, the old medina was demolished to make space for the new concrete ville moderne, precluding any possible dialogue with the physical past. Paradoxically, the obliteration of the old city did not affect the generation that witnessed it, but a few decades later the majority of the population showed nostalgia for the pre-oil town and disaffection for the urbanscape that replaced it. The conventional narrative pointed at the foreign modern architects and their supposedly technocratic approach as the leading cause for the lack of local character and the general sense of displacement. This could have been the case on several occasions, but many architects invited in Kuwait and the Gulf for the major national projects of the 1960s and 1970s belonged to a generation that already questioned orthodox functionalism and encompassed cultural relativism in their design approach. Architects usually give answers to contingent problems with the technical tools available in their time. In this case, they were also asked to realign locality and identity in the built environment and to recalibrate West-East dynamics in terms of cultural representation. The results, a sort of architectural Esperanto, not always met the patrons' expectations: often, worldwide recognizable icons were preferred to buildings which attempted to negotiate modernity with the local context.

In recent years, Kuwait has been experiencing another construction boom, boosted by a rise in the oil-price market. The concrete city of the 1960s and 1970s is now under the attack of bulldozers to make space for the new shiny glass and aluminum towers. After several decades of disaffection, the younger generation revamped interest in the post-oil city as a place of possible collective identity. While the municipal regulations and plans do not seem to prevent demolition effectively, a series of bottom-up initiatives were launched to re-engage with the city center, raise awareness and promote practices of place-making with the double outcome of fostering the sense of place and the attempt to preserving the post-oil city.

Similar trajectories can be seen in the whole region and recently some city authorities began demonstrating interest in this unclaimed heritage. In 2018, The Municipality of Dubai announced the Modern Heritage 
Initiative aiming to preserve a number of buildings from the 1970s, such as John Harris' World Trade Center and Jafar Tukan's Al Khuloud Nursery School, among others (Gulf News, August 2, 2018). Abu Dhabi as well had a similar initiative in place. These are significant indicators of reconsidering the perception of heritage, even if it is not yet clear what type of preservation is envisioned and what level re-functionalization will be permitted to keep these spaces alive. In any case, all the Gulf cities experienced similar urban development, common fate and parallel dynamics, not only in the construction of the built environment, but also in cosmopolitan aspirations and international exchanges. By being a common denominator in these processes, could modern architectural heritage become a collective element of khaliji identity?

\section{REFERENCES}

Al Sayeh, N. (2014). Modernity, Miniskirt and Cladding in Manama. In G. Arbid(Ed.), Fundamentalists and Other Arab Modernisms (p. 8). Venezia: La Biennale di Venezia.

Al Sayyad, N. (2008). From Modernization to Globalization: The Middle East in Context. In S. Isenstadt \& K. Rizvi (Eds.), Modernism and the Middle East: Architecture and Politics in the Twentieth Century (pp. 255-266). Seattle/ London: University of Washington Press.

Al-Ba'tha. (1949, February). As Cited and Translated by Al-Ragam, (2017), p. 59. Albloushi, A. (2017). To Whom Are We Giving Custody of Our Modern Architectural Heritage? In R. Camacho, S. Saragoça, \& R. Fabbri (Eds.), Essays, Arguments and Interviews on Modern Architecture Kuwait (pp. 19-36). Zurich: Niggli.

Al-Mosully, S. A. (1992). Revitalizing Kuwait's Empty City Center (Master's Thesis) MIT, Boston. Retrieved from https://dspace.mit.edu/handle/1721.1/62946

Al-Ragam, A. (2017). Towards a Critique of a Kuwaiti nahdha: Al-'imara alhaditha and the Competing Narratives on Architecture and Urban Modernity. In R. Camacho, S. Saragoça, \& R. Fabbri (Eds.), Essays, Arguments and Interviews on Modern Architecture Kuwait (pp. 47-65). Zurich: Niggli.

Al-Taher, I. (1995). Kuwait the Reality. Pittsburgh: Dorrance Publishing Co.

Andraos, A. (2016). Arab City in Representation. In A. Andraos, \& N. Akawi (Eds.) with C. Blanchfield, The Arab City: Architecture and Representation (pp. 7-20). New York: Columbia Books on Architecture and the City.

Banks, R. L. (1955). Notes on a Visit to Kuwait. The Town and Planning Review, $26(1), 48-50$.

Barron, D. G. (1967). Kuwait the Design of Schools and Related Problem. Paris: UNESCO. 
Botz-Bornstein, T. (2017). Transcultural Architecture: The Limits and Opportunities of Critical Regionalism. London: Routledge.

Broeze, F. (1997). Gateways of Asia: Port Cities of Asia in the 13th-20th Centuries. London: Kegan Paul.

Camacho, R., Saragoça, S., \& Fabbri, R. (Eds.). (2017). Essays, Arguments \& Interviews on Modern Architecture Kuwait. Zurich: Niggli.

De Carvalho, G. (1965, September 17). Everything Is Up to Date in Kuwait. LIFE, 96-108.

Dirlik, A. (2000). Is There History After Eurocentrism? Globalism Postcolonialism, and the Disavowal of History. In A. Sirlik, V. Bahl, \& P. Gran (Eds.), History After the Three Worlds: Post Eurocentric Historiographies (pp. 25-48). Oxford: Rowman and Littlefield.

Dubai to Preserve Modern Heritage Under New Initiative. (2018, August 2). Gulf News. Retrieved September 4, 2018 from http://gulfnews.com/news/ uae/culture/dubai-to-preserve-modern-heritage-buildings-under-newinitiative-1.2260871

Fabbri, R. (2016, Autumn). Iconicity: Seeking Identity by Building Iconic Architecture in Kuwait. In M. Karolak (Ed.), Gulf Affairs. Identity and Culture in the $21^{\text {st }}$ Century Gulf (pp. 13-16).

Fabbri, R., Saragoça, S., \& Camacho, R. (2016). Modern Architecture Kuwait: 1949-1989. Zurich: Niggli.

Fourth Structural Plan Turns Kuwait into Commercial, Financial Hub: PM. (2016, November 23). Kuwait Times, p. 4.

Frazer, J. E. (1965, May). Kuwait. The Aladdin's Lamp in the Middle East. National Geographic, 135(8), 335-367.

Freeth, Z. (1956). Kuwait Was My Home. London: George Allen \&Unwin.

Garcia, B. (2014, April 4). Architects Seek Preservation of Building in Mubarakiya. Kuwait Times. Retrieved September 4, 2018 from http://news.kuwaittimes. net/architects-seek\%2D\%2Dbuilding-mubarakiya/preservation

General Secretariat of the Supreme Council for Planning and Development of the State of Kuwait. (2015). New Kuwait-Urban Development Plan 2015-2020. Retrieved May 10, 2018 from http://www.newkuwait.gov.kw/en/

Gieseking, J. J., \& Mangold, W. (2014). The People, Place, and Space Reader. New York: Routledge.

Hussain, H. (Director). (1992). Kuwait Architecture: A Lost Identity. [VHS]. Kuwait: Dar al-Athar al-Islamiyyah.

Jonathan, C. R. (1981, March 3). 1929-1981: A Briton's Life in Kuwait. Washington Post. Retrieved May 10, 2018 from https://www.washingtonpost. com/archive/politics/1981/03/03/1929-1981-a-britons-life-in-kuwait/

KEG, \& Colin Buchanan and Partners. (2005). Third Kuwait Masterplan Review: Executive Summary. Kuwait City: Kuwait Municipality. 
Lanzl, C., Tullis, R., \& Schultz, A. (2017). Placemaking Manifesto 2007-2017. Retrieved September 4, 2018 from https://www.architects.org/committees/ news/placemaking-manifesto-public-discussion

Lewis, B. (1968). The Emergence of Modern Turkey. Oxford: Oxford University Press.

Lewis, B. (1992). The Muslim Discovery of Europe. New York: W.W. Norton.

Mahgoub, Y. (2007). Architectural and the Expression of Cultural Identity in Kuwait. The Journal of Architecture, 12(2), 165-182.

Marcuse, H. (1964). One-Dimensional Man: Studies in the Ideology of Advanced Industrial Society. Boston: Beacon Press.

Nuqat Kuwait City. (2014, March 1). Retrieved May 15, 2018 from http://tashkeel.org/residencies/updates/nuqat-kuwait-city

Proshansky, H. M., Fabian, A. K., \& Kaminoff, R. (1983). Place-Identity: Physical World Socialization of the Self. Journal of Environmental Psychology, $57(3), 57-83$.

Rosenberg, H. (1959). The Tradition of the New. New York: Horizon Press.

Shiber, S. G. (1964). The Kuwait Urbanization: Documentation, Analysis, Critique. Kuwait: Kuwait Government Printing Press.

Sudjic, D. (2005). The Edifice Complex: How the Rich and Powerful Shape the World. London: Penguin Books Ltd.

UNHABITAT. (2016). National Report: Kuwait Housing and Sustainable Urban Development, United Nations Conference of Housing and Sustainable Development-Habitat III. Quito.

Viadotto, M. (1997). Allison \& Peter Smithson: Obras y proyectos. Works and Projects. Barcelona: GG.

Watenpaugh, K. D. (2014). Being Modern in the Middle East. Princeton: Princeton University Press.

Wright, G. (2016). Architects as Migrants. In A. Andraos \& N. Akawi (eds.) with C. Blanchfield, The Arab City: Architecture and Representation (pp. 74-77). New York: Columbia Books on Architecture and the City. 
Open Access This chapter is licensed under the terms of the Creative Commons Attribution 4.0 International License (http://creativecommons.org/licenses/ by $/ 4.0 /$ ), which permits use, sharing, adaptation, distribution and reproduction in any medium or format, as long as you give appropriate credit to the original author(s) and the source, provide a link to the Creative Commons licence and indicate if changes were made.

The images or other third party material in this chapter are included in the chapter's Creative Commons licence, unless indicated otherwise in a credit line to the material. If material is not included in the chapter's Creative Commons licence and your intended use is not permitted by statutory regulation or exceeds the permitted use, you will need to obtain permission directly from the copyright holder.

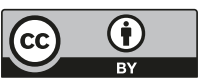

